\title{
Discussion to the paper by W. M. Mee
}

WALTERS. Some workers failed to confirm Fine's work because (Fine said) the dogs they used were resistant to the antibiotics given to sterilize the intestine. When animals with different organisms were substituted, they were able to confirm his experiments.

Wright. Fine, I believe, also found that he could kill dogs pre-treated with thorotrast by a single dose of a wide-spectrum antibiotic. This is fair evidence of sudden release and absorption of endotoxin. Has this been confirmed elsewhere?

STONER. It is not generally realized that the doses of thorotrast and other reticulo-endothelial (RE) blocking agents used by Fine are rather toxic. They can all cause liver damage as well as damaging the RE cells. If the doses are reduced so that they still block the RE cells without damaging the liver, or if small doses of beryllium are used, there is no potentiation of, say, tourniquet injury. There is much less evidence that if the activity of the RE system is increased there is any improvement in these animals. In the rat, boosting the activity of the RE system causes no difference in the response to tourniquet injury. According to Fine this is not an irreversible form of shock, but it certainly kills the animal. Fine does not go into the relative sensitivity of each species to endotoxin, and the rat is not very sensitive.

Hopkin. I understood Mr Mee to say that if blood from a shocked dog is put into a pre-treated shocked dog, the dog dies of irreversible shock. Could it not be that you are giving a large dose of adrenaline and noradrenaline in the transfused blood, and that this is what does the damage and not the endotoxin?

I have always been interested in the work of Reilly in France (Hopkin, 1959) with endotoxin. He showed that small experimental animals, guinea-pigs and rabbits, could safely be given pretty large doses of endotoxin intravenously, but if a minute quantity of endotoxin was put on autonomic nerves in the abdomen, especially the splanchnic, the animal was liable to die within $24 \mathrm{hr}$. One of his pupils who found that it was very difficult to produce such reactions consistently in dogs, discovered that if he injected a very small dose of typhoid antigen directly into the fourth ventricle 'the dog plunged immediately into a typhoid state' (Tardieu, 1942). I think the effects of endotoxin are primarily neurogenic.

MEE. Fine has repeated this work of injecting endotoxin into the fourth ventricle and agrees that it does produce a state of shock.

With regard to the noradrenaline hypothesis, a state of bloody diarrhoea and shock can be produced, but you have to give the noradrenaline repeatedly over a long period.

IRVING. Could I ask Mr Mee to comment on the extrapolation of Fine's work into the clinical situation? Fine says that this has clinical application; he uses regional blockade of the coeliac region with local anaesthetic together with massive doses of steroids. Do you think that this is clinically valid?

MEE. I would hesitate to open someone's abdomen and try to dissect out the coeliac ganglion if they were already in a state of irreversible shock. It must also be extremely difficult to place injections of anaesthetic around the coeliac ganglion in such a patient. There is some work indicating that steroids do protect in endotoxin shock.

\section{References}

HopkIN, D.A.B. (1955) The action of chloropromazine. Review of French work. Lancet, i, 605.

TARDIEU, G. (1942) Le typhos. Etude physio-pathologique de l'atteinte du diencéphale au cours de la fièvre typhoide. Présse. Med. 50, 75. 